\title{
Heterogeneous Oxidation of Alkenes: The Role of Silica-supported Bimetallic and Trimetallic Catalysts
}

\author{
Hitesh M. Parekh ${ }^{\mathrm{a}, \mathrm{b}, *}$, Jignesh K. Valand ${ }^{\mathrm{b}}$ and Holger B. Friedrich ${ }^{\mathrm{b}}$ \\ ${ }^{a}$ Department of Chemistry, School of Sciences, Gujarat University, Navrangpura, Ahmedabad 380009, India. \\ ${ }^{b}$ School of Chemistry \& Physics, University of KwaZulu-Natal, Westville Campus, Durban, 4000, South Africa.
}

Received 6 June 2016, revised 5 September 2016, accepted 14 September 2016.

\begin{abstract}
Silica-supported bimetallic and trimetallic transition metal catalysts with different metal loadings of $\mathrm{Cu}$, $\mathrm{Ni}$ and Co have been prepared by using the ultrasonic cavitation-impregnation method. The characterization of the prepared catalysts was done by BET, SEM-EDS, TEM and powder XRD. The catalytic activity was tested in the liquid phase oxidation of styrene, 4-chloro styrene and cyclohexene using tert-butyl hydroperoxide (TBHP) as the oxidant and acetonitrile as a solvent under mild conditions. In styrene oxidation, the trimetallic catalyst $30 \mathrm{CuNiCoSiO}$ showed a maximum of $95 \%$ conversion with $74 \%$ benzaldehyde and $25 \%$ styrene oxide selectivity at the end of the $24 \mathrm{~h}$ reaction time at $40{ }^{\circ} \mathrm{C}$. The catalysts could be recycled three times without losing their catalytic activity and no metal species leached out from the support.
\end{abstract}

KEYWORDS

Silica, trimetallic catalysts, styrene, catalytic activity, oxidation.

\section{Introduction}

For the production of industrial chemicals from hydrocarbon feed stocks, catalytic oxidation is one of the most viable techniques which attracted attention in the field of catalysis. ${ }^{1}$ Conversely, for the production of the fine chemicals, numerous works were done in the past few decades in the field of oxidation catalysis using stoichiometric quantities of inorganic and organic oxidants. Increasing environmental awareness has resulted in the prohibition of such processes and has stimulated the development of catalytic alternatives. ${ }^{2}$ Heterogeneous catalysis is preferred over homogeneous catalysis for the oxidation, as heterogeneous catalysts can be recycled to use for continuous processing. ${ }^{1,2}$ The oxidative functionalization of olefins is of significant importance in the fine chemicals and pharmaceutical industries, since the oxidized products are key building blocks in organic synthesis. ${ }^{3-5}$ Benzaldehyde is one of the most valueadded products, which is formed via the oxidation of olefins like styrene. Benzaldehyde is the simplest representative of the aromatic aldehydes and is used mainly in the preparation of dyes, adhesives and paints. ${ }^{6}$ Manufacturing of value-added products like benzaldehyde through homogeneous catalysis is possibly a viable route, which has been explored over the past few decades. ${ }^{7}$ However, separation and reusing of the homogeneous catalysts for these reactions is challenging and render the complete process economically unviable for industrial applications, more so for expensive catalysts with low turnover numbers. $^{8}$

Oxidative functionalization of styrene to produce styrene oxide and benzaldehyde was done over supported precious metal oxides like Au and Ag. ${ }^{911}$ Due to the high cost of the precious metals, alternative routes need to be investigated. Indeed, it is well known that supported transition metal (e.g. Cu, Co and V) oxides are active homogeneous catalysts for olefin oxidation. ${ }^{12,13}$ For the heterogeneous oxidation of alkenes, there are a number of reports involving the use of mono and bimetallic-supported

* To whom correspondence should be addressed. E-mail: keya714@gmail.com metal oxides ${ }^{14-17}$ In addition to that, oxidation of cyclohexene by TBHP catalyzed by a series of titania-silica $\left(\mathrm{TiO}_{2}-\mathrm{SiO}_{2}\right)$ mixed oxides prepared by a sol-gel procedure was studied and the effect of water in the reaction medium has also been investigated by Figueras and Kochkar. ${ }^{18}$ Titanium oxide-supported zeolite particles have been used as a heterogeneous catalytic system for the oxidation of alkenes with $\mathrm{H}_{2} \mathrm{O}_{2}$ as reported by Nur et al. ${ }^{19}$, while Nieet et al. studied the use of $\mathrm{TiO}_{2}$ and $\mathrm{TiO}_{2} / \mathrm{SiO}_{2}$ as catalysts for the oxidative conversion of styrene to benzaldehyde using $\mathrm{O}_{2}$ as oxidant. ${ }^{20}$ Furthermore, the oxidation of various cyclic and linear alkenes was studied by Savalati and Rasouli ${ }^{21}$ using supported heteropolymolybdate nanoparticles between silicate layers of bentonite and $30 \% \mathrm{H}_{2} \mathrm{O}_{2}$ as the oxidizing agent.

Many reports are available in the literature on mesoporous materials that have been considered as promising catalyst supports with high surface areas, defined pore-size and stability. ${ }^{22-25}$ In addition, the application of mesoporous materials as catalysts and catalyst supports has been reviewed..$^{26,27}$ The specific mesoporous material chosen, with transition metal oxides, might enhance the catalytic activity in alkene oxidation reactions. In spite of many efforts to increase the conversion and selectivity to desired products in alkene oxidation, only a few catalytic systems with multi transition metal oxides have been developed, with very few reports on trimetallic catalyst systems. One of the greater disadvantages of using metal oxide-supported catalysts is leaching of the metal from the catalyst. This could be due to the support and the preparation method of the catalyst. ${ }^{28}$ Bimetallic supports like $\mathrm{SiO}_{2}-\mathrm{TiO}_{2}{ }^{20} \mathrm{SiO}_{2}-\mathrm{Al}_{2} \mathrm{O}_{3}{ }^{29} \mathrm{TiO}_{2}-\mathrm{ZrO}_{2}{ }^{29}$ (silica, alumina, titania, zirconia) have been explored to overcome the problem of leaching of the metal from the support. ${ }^{30}$

Recently, we reported the catalytic activity towards styrene oxidation of trimetallic catalysts supported on $\gamma$-alumina prepared by using the ultrasonic cavitation-impregnation method. ${ }^{31}$ Slight leaching of copper from the catalysts, which might be due to weak interaction of copper to the support, resulted in changing selectivities on recycling. In order to extend the scope of the 
work in the heterogeneous oxidation of alkenes, we have carried out this new study using bimetallic and trimetallic catalysts. In the present paper, preparation of silica-supported bimetallic and trimetallic catalysts, their characterization and application for oxidative functionalization of the olefins like styrene, 4-chlorostyrene and cyclohexene using TBHP as the oxidant have been summarized.

\section{Experimental Details}

\subsection{Catalyst Preparation}

Silica-supported trimetallic and bimetallic oxides were prepared by using the ultrasonic cavitation-impregnation method. The required quantity of the metal precursors, $\mathrm{Cu}\left(\mathrm{NO}_{3}\right)_{2} 3 \mathrm{H}_{2} \mathrm{O}$ (Sigma-Aldrich), $\mathrm{Ni}\left(\mathrm{NO}_{3}\right)_{2} 6 \mathrm{H}_{2} \mathrm{O}$ (Sigma-Aldrich) and $\mathrm{Co}\left(\mathrm{NO}_{3}\right)_{2}$ $6 \mathrm{H}_{2} \mathrm{O}$ (ACE) were dissolved in distilled water and added to silica (Alfa-Aesar). Magnetic stirring of $300 \mathrm{rpm}$ and ultrasonic cavitation at $43 \mathrm{KHz}$ frequency (MRC Ultrasonic System, D150H) was applied at room temperature for better dispersion of the metal followed by evaporation at $70{ }^{\circ} \mathrm{C}$. After the evaporation step, drying was carried out at $110{ }^{\circ} \mathrm{C}$ for $16 \mathrm{~h}$ and then calcined at $550^{\circ} \mathrm{C}$ for $5 \mathrm{~h}$, to get catalysts with the total 5 (3:1.5:0.5), 10 (6:3:1), 20 (12:6:2) and 30 (18:9:3) wt\% metal loadings and composition (details are mentioned in Table 1).

\subsection{Characterization Techniques}

Textural properties of catalyst samples were measured by $\mathrm{N}_{2}$ adsorption-desorption isotherms obtained at $-196{ }^{\circ} \mathrm{C}$. The Brunauer-Emmett-Teller (BET) surface area was measured using a Micromeritics Tristar II surface area and porosity analyzer. Catalyst morphology was observed under a Zeiss 'Ultra plus' scanning electron microscope (SEM). Transmission electron microscopy (TEM) samples were prepared by immersing the catalyst powder in ethanol and this suspension placed under ultrasonication then dropped onto amorphous carbon films supported copper grids, followed by evaporation at ambient conditions. TEM analysis was performed with a Jeol JEM-1010 Electron Microscope. Different metal oxide phases in the catalysts were detected using powder X-ray diffraction (XRD) performed on a Bruker D8 Advance instrument, a Cu radiation source with a wavelength of $1.5406 \lambda$, diffractograms were recorded over the range $15-90^{\circ}$ with a step size of 0.5 per second.

\subsection{Catalysis Testing}

The alkene oxidation was carried out in a 50-mL two-necked, pear-shaped flask equipped with a condenser in an oil bath with magnetic stirring. Oxidation studies were carried out in the different experiments for $24 \mathrm{~h}$ at $40^{\circ} \mathrm{C}$ temperature by using suitable catalyst $(5 \mathrm{mg})$ and substrates like styrene $(0.96 \mathrm{mmol})$ 4-chlorostyrene $(0.72 \mathrm{mmol})$, cyclohexene $(1.21 \mathrm{mmol})$ in $\mathrm{CH}_{3} \mathrm{CN}$

Table 1 Surface area and metal composition of the catalysts.

\begin{tabular}{lcccc} 
Sample & $\begin{array}{c}\text { BET surface } \\
\text { area } \\
/ \mathrm{m}^{2} \mathrm{~g}^{-1}\end{array}$ & $\begin{array}{c}\text { Total pore } \\
\text { volume } \\
/ \mathrm{cm}^{3} \mathrm{~g}^{-1}\end{array}$ & $\begin{array}{c}\text { Average pore } \\
\text { size } \\
/ \mathrm{nm}\end{array}$ & $\begin{array}{c}\text { Metal loadings } \\
(\mathrm{Cu}, \mathrm{Ni}, \mathrm{Co}) \mathrm{wt} \text { \% }\end{array}$ \\
\hline Silica & 136 & 0.53 & 17.80 & - \\
$\mathrm{CuNiSiO}$ & 119 & 0.43 & 14.77 & $(6,3)$ \\
$\mathrm{NiCoSiO}$ & 129 & 0.47 & 14.62 & $(3,1)$ \\
$\mathrm{CuCoSiO}$ & 126 & 0.45 & 14.63 & $(6,1)$ \\
5CuNiCoSiO & 132 & 0.53 & 16.15 & $(3,1.5,0.5)$ \\
10CuNiCoSiO & 122 & 0.48 & 15.84 & $(6,3,1)$ \\
20CuNiCoSiO & 98 & 0.38 & 15.54 & $(12,6,2)$ \\
30CuNiCoSiO & 85 & 0.32 & 15.38 & $(18,9,3)$ \\
\hline
\end{tabular}

$(2.5 \mathrm{~mL})$ as a solvent. The molar ratio of alkenes to TBHP $(70 \%$ in water) was kept constant (1:1.5) for the reactions. On the basis of our previous study ${ }^{31}$ and by doing the set of experiments in the present study, the catalytic reaction conditions were optimized. Alkene oxidation experiments were done in triplicate under similar conditions with fresh catalysts. The reactants and products of the reaction were calculated by gas chromatography analysis equipped with a capillary column (Varian, CB Sil5, $25 \mathrm{~m} \times$ $0.15 \mathrm{~mm} \times 2 \mu \mathrm{m})$ and an FID detector. To quantify all the components of the oxidation reaction, chlorobenzene was used as an internal standard. For the selectivity calculations, the products with a benzene ring were considered. The carbon balances ranged between 91 to $93 \%$ and the rest of the product is carbon dioxide. All the catalytic tests were done in triplicate and the results obtained were in the standard deviation of $\pm 2 \%$.

\section{Results and Discussion}

\subsection{Characterization}

The isotherms indicate IUPAC type IV patterns with type H2 hysteresis loop, identifying the presence of mesopores (Fig. 1). These catalysts have narrow pore size distribution of the mesopores (Fig. 1b).

Figure 1a represents the nitrogen adsorption-desorption isotherms of the catalysts. BET results show that the texture of the catalysts was strongly dependent on the total metal loadings, resulting in significant changes in textural properties of the catalyst (Table 1). Major changes in textural properties were found for the bimetallic and trimetallic catalyst samples. The highest metal loaded catalyst $30 \mathrm{CuNiCoSiO}$ showed $85 \mathrm{~m}^{2} \mathrm{~g}^{-1}$ surface
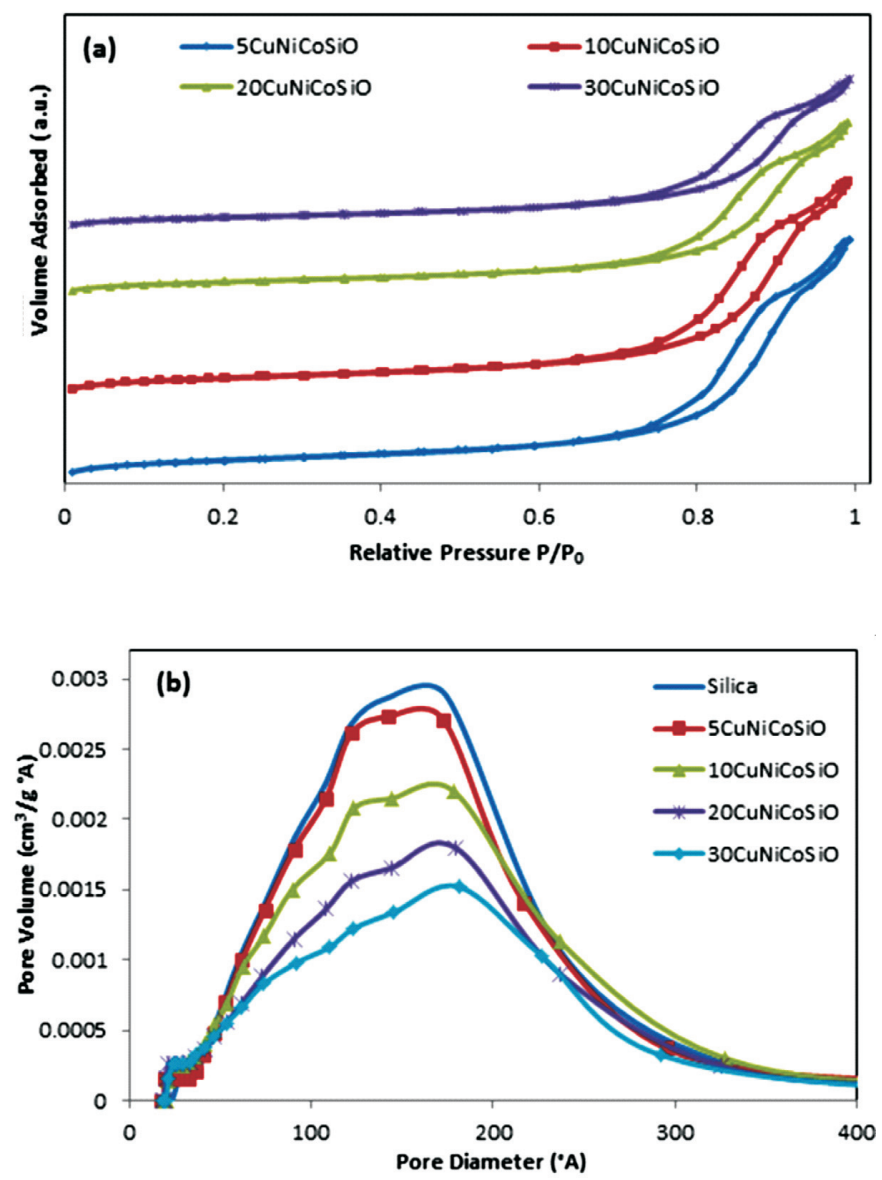

Figure 1 (a) $\mathrm{N}_{2}$ adsorption-desorption isotherms and (b) pore size distribution of ternary catalysts. 
area, which is low compared to silica itself, i.e. $136 \mathrm{~m}^{2} \mathrm{~g}^{-1}$. The same trend was observed in terms of pore volume and pore size. It was found that pore volume decreased gradually from $0.48 \mathrm{~cm}^{3} \mathrm{~g}^{-1}$ to $0.32 \mathrm{~cm}^{3} \mathrm{~g}^{-1}$ in the case of $10 \mathrm{wt} \%$ to $30 \mathrm{wt} \%$ metal loaded catalysts, respectively. This means that higher amounts of metals on the surface cover the silica surface as well as go inside the pores. To a certain extent the metal particles also agglomerate on the support surface. In this case, it is very important to improve the metal dispersion and distribution to enhance the catalyst activity, mainly by changing the metal loadings and/or by varying the parameters in the catalyst preparation method.

In the literature, ${ }^{32}$ it was also reported that the metal oxides agglomerate on the silica support and to understand the effect of metal dispersion on support, it was decided to start with a metallic ratio of $6: 3: 1$ of $\mathrm{Cu}: \mathrm{Ni}: \mathrm{Co}$.

The powder XRD patterns (Fig. 2) of the ternary oxides on the silica support show the presence of metal oxides phases. The oxide phases of all three metals, i.e. $\mathrm{CuO}$ (JCPDS 5-066), $\mathrm{NiO}$ (JCPDS 4-00835), $\mathrm{Co}_{3} \mathrm{O}_{4}$ (JCPDS42-1467) and support, i.e. pure amorphous silica (JCPDS 29-0085) were observed in the diffractogram. Higher metal loading in the case of $30 \mathrm{CuNiCoSiO}$ is mainly responsible for the increase in peak intensity of the metal oxides due to greater amounts of oxides present on the silica and it also gives indication of metal oxide particles agglomerated on the support. The intensity of metal oxides peaks in the case of $10 \mathrm{CuNiCoSiO}$ is lower than $30 \mathrm{CuNiCoSiO}$, which means that metals may be less agglomerated on the support. The metal-support interaction is a very important factor for catalytic activity and, therefore, good metal dispersion and distribution on a support like silica improves the oxygen transfer capacity of the system, making the oxygen more available and ultimately it enhances the rate of the oxidation reaction of suitable chemical moieties.

The presence of the metal particles on the silica surface is clearly visible as shown in the scanning electron micrographs (Fig. 3a,b,c). Arrows in the figure, indicate the presence of metal particles on the support.

Metal dispersion on the support is also a very important property for catalytic study and SEM-EDS is a good technique to observe it. Therefore, metal dispersion and distribution on silica were confirmed by EDS mapping for $10 \mathrm{CuNiCoSiO}$ catalyst (Fig. 4). The inset plot in the EDS mapping shows the presence of all three metals in the case of $10 \mathrm{CuNiCoSiO}$.
In this study, three catalysts with different metal loadings have been prepared to investigate the effect of metal dispersion. It can be seen from Fig. 3d,e,f), that as the metal loading increases from 10 to $30 \mathrm{wt} \%$, the size of the catalyst particles also increases due to agglomeration of the particles. The catalyst with the lowest metal loading, $10 \mathrm{CuNiCoSiO}$, shows better dispersion and little agglomeration. SEM and TEM studies revealed the relation between metal loadings and metal dispersion of the resultant ternary catalysts.

\subsection{Catalytic Activity}

In literature, mostly TBHP and hydrogen peroxide were found to be the best oxidizing agents in this type of oxidation reaction. ${ }^{9,16,20}$ Both TBHP and $\mathrm{H}_{2} \mathrm{O}_{2}$ were studied for the styrene oxidation in this work, but THBP was found to be the best source of oxygen. Styrene was chosen as substrate model for the optimization of the catalysis reaction conditions using TBHP as the oxidant in the presence of catalytic amounts of the $10 \mathrm{CuNiCoSiO}$ catalyst. The optimized reaction conditions were found to involve a substrate to oxidant molar ratio of 1:1.5. Under these optimum reaction conditions, the oxidation of styrene was studied at room temperature, $40^{\circ} \mathrm{C}$ and $55^{\circ} \mathrm{C}$. Since the rate of reaction was very low at room temperature and the selectivity to benzaldehyde and styrene oxide was poor at $55^{\circ} \mathrm{C}$, the reaction temperature was set at $40^{\circ} \mathrm{C}$. Two different solvents, namely dichloromethane and acetonitrile, were examined. The best performance of the catalyst was obtained in acetonitrile, possibly due to its dielectric constant $\left(\varepsilon / \varepsilon_{0}=37.5\right)$ which is higher than that of dichloromethane, and this polarity gives higher solubility of all reagents. The catalytic tests were performed in triplicate and the results obtained were in the standard deviation of $\pm 2 \%$.

\subsubsection{Catalytic Oxidation of Styrene}

A blank oxidation reaction was performed in the absence of catalyst under the optimum conditions to account for the involvement of TBHP in the styrene oxidation reaction and $20 \%$ styrene conversion was achieved without catalyst.

To identify the role of bimetallic catalysts with the same intermetallic ratios, catalysts $\mathrm{CuNiSiO}, \mathrm{NiCoSiO}$ and $\mathrm{CuCoSiO}$ supported on silica were prepared and tested for styrene oxidation under similar reaction conditions. Catalysis results show $62 \%, 51 \%$ and $64 \%$ styrene conversion, respectively (Fig. 5).

The selectivities of benzaldehyde were found to be in the

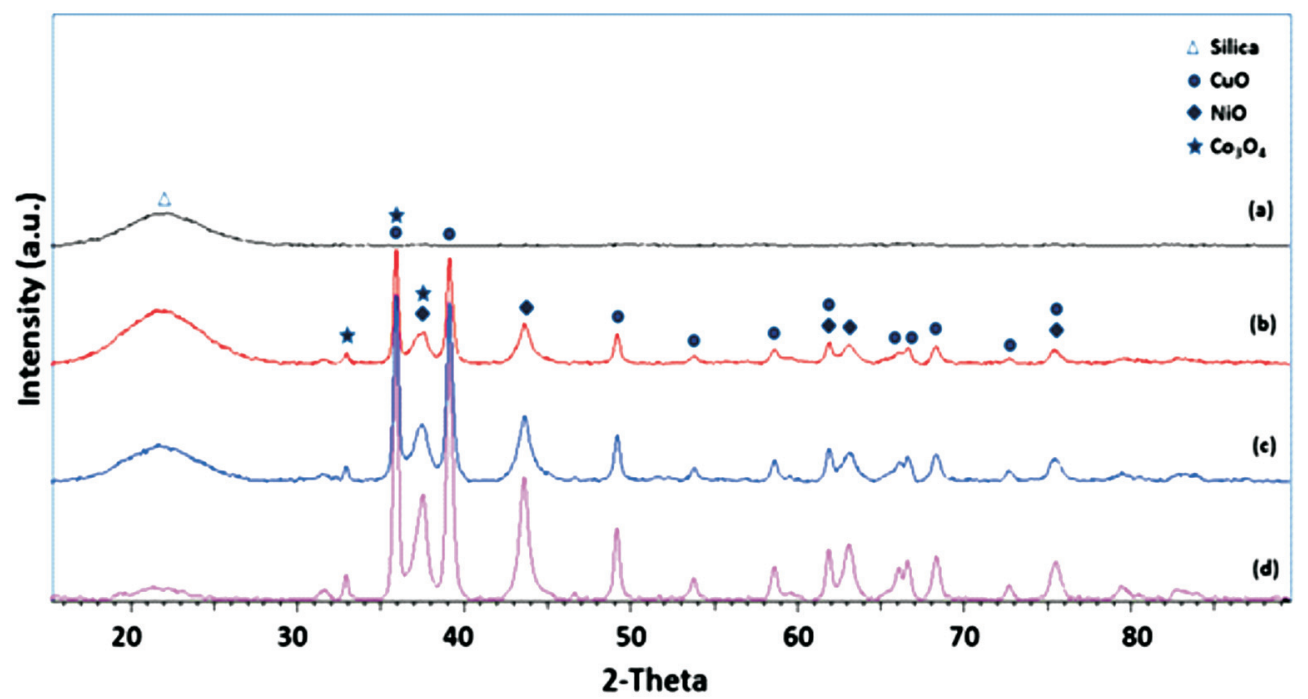

Figure 2 Powder XRD of (a) silica, (b) 10CuNiCoSiO, (c) $20 \mathrm{CuNiCoSiO}$ and (d) $30 \mathrm{CuNiCoSiO}$ trimetallic catalysts. 


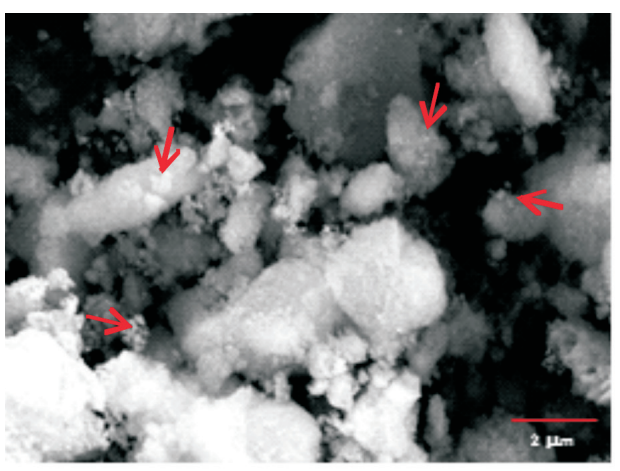

(a)

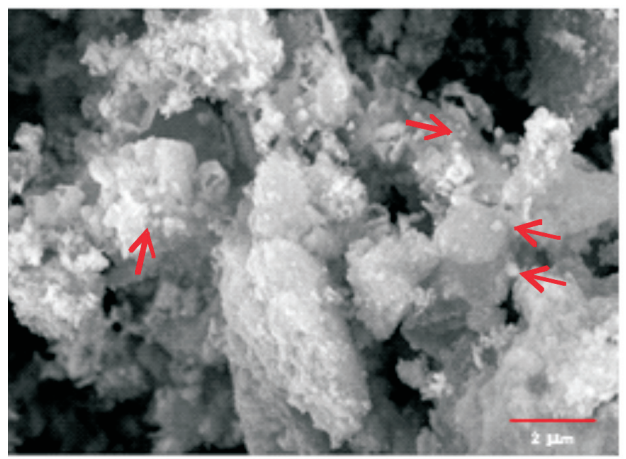

(c)

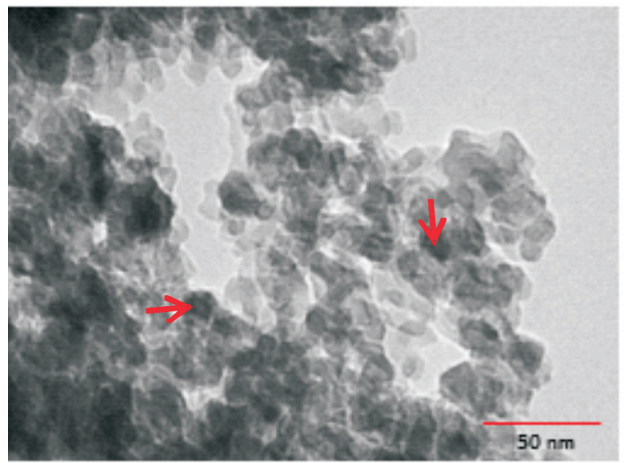

(e)

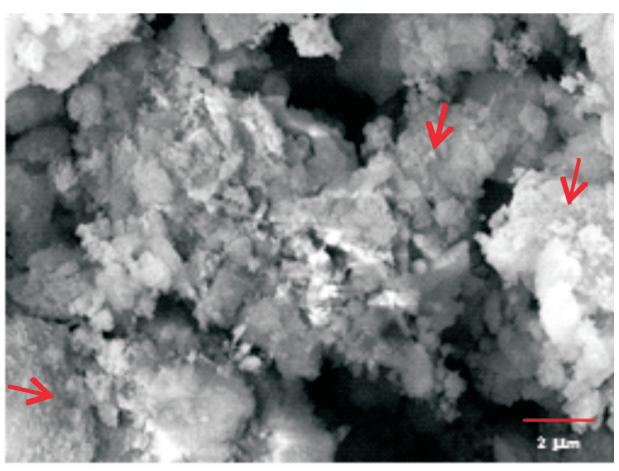

(b)

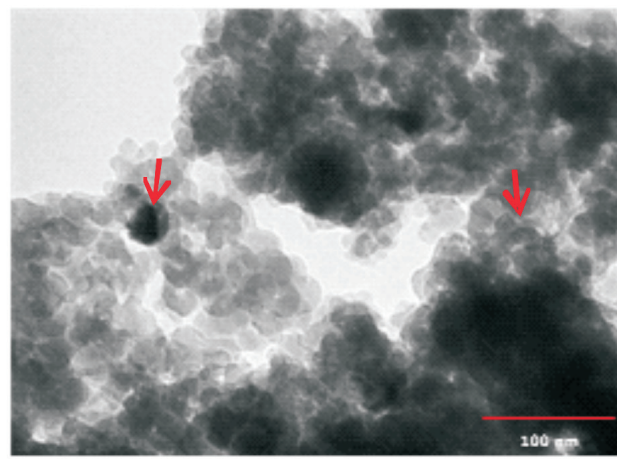

(d)

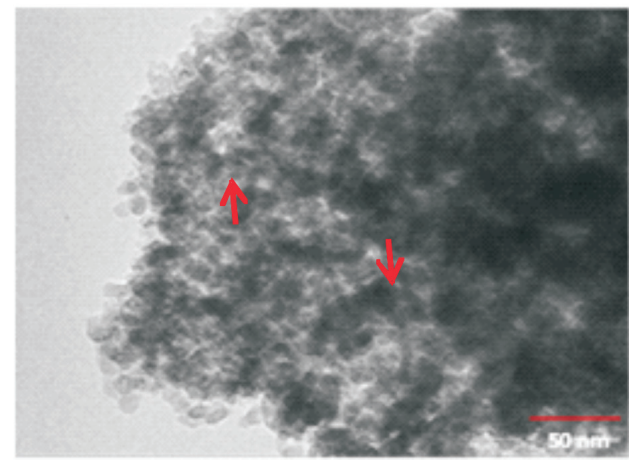

(f)

Figure $3(\mathbf{a}, \mathbf{b}, \mathbf{c}) \mathrm{SEM}$ and $(\mathbf{d}, \mathbf{e}$,f) TEM images of the $10 \mathrm{CuNiCoSiO}, 20 \mathrm{CuNiCoSiO}$ and $30 \mathrm{CuNiCoSiO}$ catalysts, respectively.

range of $56-66 \%$, styrene oxide in the range of $12-23 \%$ and other products in the range of $13-32 \%$. To study the effect of more than two metals in terms of catalyst activity of the trimetallic catalysts, 5 to $30 \mathrm{wt} \%$ total metal loadings of copper, nickel and cobalt on silica were prepared and it was found that even the $5 \mathrm{CuNiCoSiO}$ trimetallic catalyst showed higher conversion than the bimetallic catalysts, even though the total metal loading is lower than in the bimetallic catalysts. Synergistic effects are experienced among all the metals during reaction and they may be responsible for enhancing the catalytic activity in the case of the trimetallic catalysts. Therefore, further catalytic studies on the trimetallic catalysts were carried out with different substrates.

The styrene conversion increased with the increase in the metal loading from 5 to $30 \mathrm{wt} \%$ in the case of trimetallic catalysts (Fig. 6). Catalytic performance depends on the active sites of the catalysts. Higher conversion was possible in the case of ternary metal based catalyst, as it provides more active sites. The benzaldehyde selectivity increased from 63 to $74 \%$ and the selectivity of styrene oxide increased from 22 to $25 \%$ with increasing total metal loadings at the end of the $24 \mathrm{~h}$ reaction period (Fig. 6). The other products, i.e. 1-phenylethane-1,2-diol, acetophenone and phenyl acetaldehyde selectivity fall in the range of 1 to $15 \%$, in all reactions after $24 \mathrm{~h}$. Thus in the case of the $5 \mathrm{CuNiCoSiO}$ catalyst the total selectivity of other products was found to be $15 \%$, for the $10 \mathrm{CuNiCoSiO}$ catalyst $13 \%$, for the $20 \mathrm{CuNiCoSiO}$ catalyst $9 \%$ and for the $30 \mathrm{CuNiCoSiO}$ catalyst only $1 \%$. So, appropriate metal loading is also a very important factor to get higher conversion with better selectivity of the desired product.

Acidity of the catalyst and distribution of acidity are very important factors in the field of catalysis. Overall acidity of the catalyst mainly depends on the nature of metal and support present in the catalyst. In literature, it has been reported that oxides of $\mathrm{Ni}$ and $\mathrm{Cu}$ show greater Brønsted acidity than $\mathrm{Co}$ oxide. ${ }^{33}$ Due to the high Lewis basic nature of the cobalt, the ternary catalyst contains an even distribution of basic and acidic sites. Brønsted acidity is responsible for adsorption of oxidants on the catalysts surface and the oxygen from the oxidant desorbs due to the Lewis acidic nature. ${ }^{34} \mathrm{~A}$ comparison of the heterogeneous catalysts used in this study with some reported heteroge- 


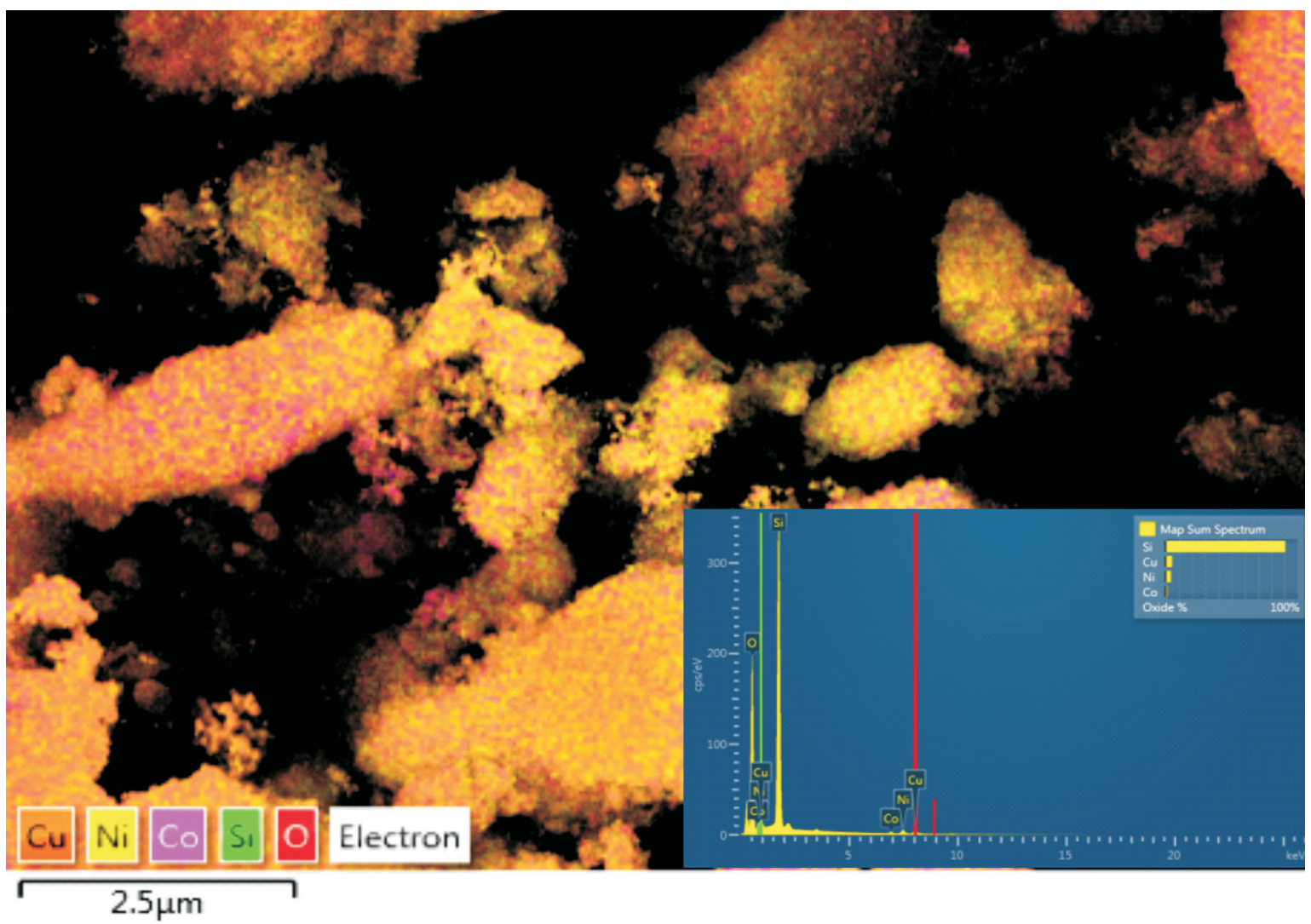

Figure 4 SEM-EDS mapping of the $10 \mathrm{CuNiCoSiO}$ catalyst.

neous catalyst systems for styrene oxidation is shown in the supplementary information (Table S1). Among all the metals and metal oxides supported on different supports reported in literature (Table S1), the $30 \mathrm{CuNiCoSiO}$ trimetallic catalyst shows best performance in terms of conversion and selectivity to benzaldehyde. The further advantage of this catalyst is that only a very small amount of $5 \mathrm{mg}$ is needed and the operating temperature is low $\left(40^{\circ} \mathrm{C}\right)$.

After obtaining encouraging catalytic results in styrene oxida- tion and to possibly extend the scope of this trimetallic catalytic system, the oxidation of other substrates was carried out under the optimized reaction conditions.

\subsubsection{Catalytic Oxidation of 4-Chlorostyrene}

In order to investigate the performance of the trimetallic catalyst system on an electron deficient system, the oxidation of 4-chlorostyrene was carried out under the optimum reaction conditions (Fig. 7). The results indicate that, as the metal loading

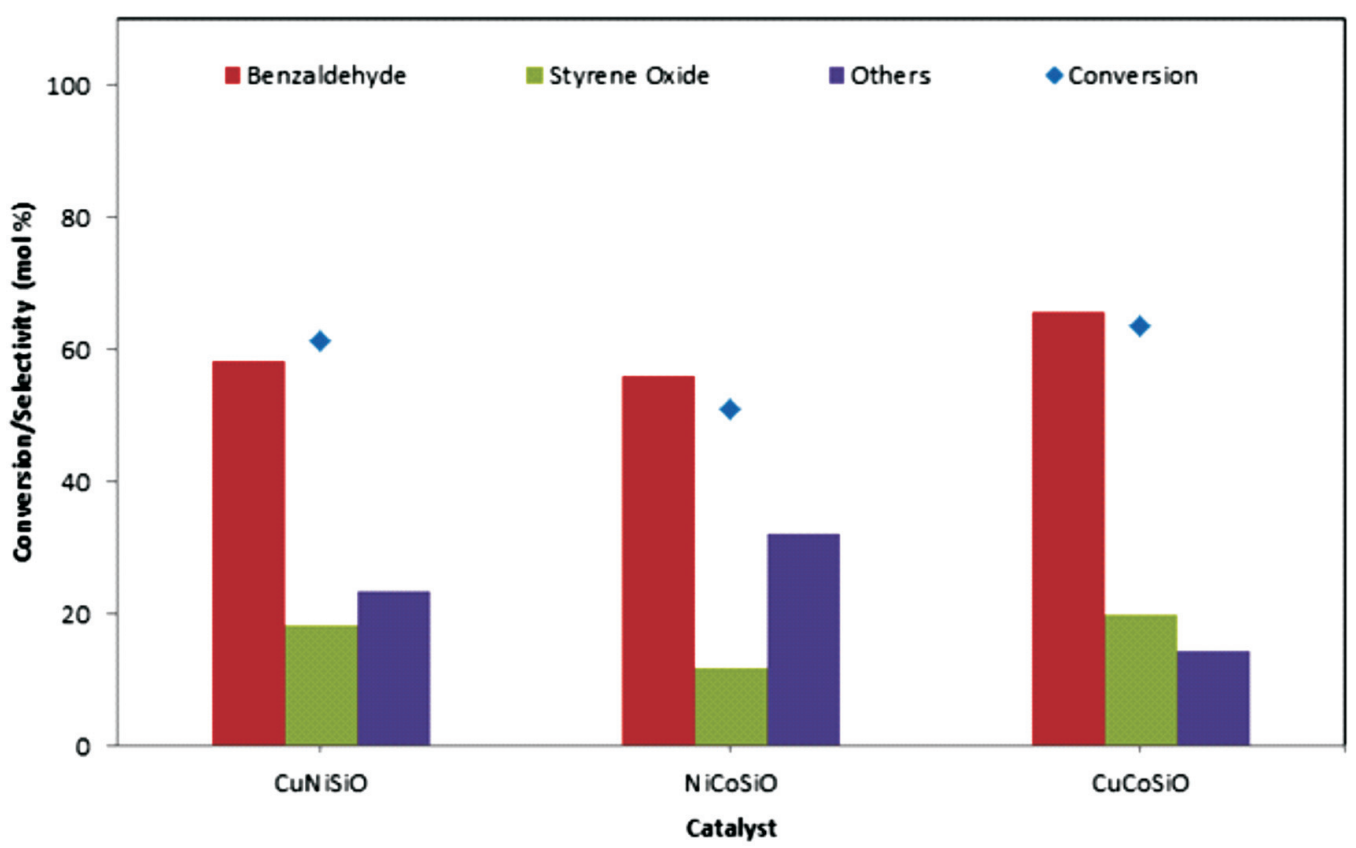

Figure 5 Conversion and selectivity of the bimetallic catalysts for styrene oxidation at $40{ }^{\circ} \mathrm{C}$ after $24 \mathrm{~h}(5 \mathrm{mg}$ catalyst, $0.96 \mathrm{mmol}$ styrene in $2.5 \mathrm{~mL}$ $\mathrm{CH}_{3} \mathrm{CN}$, alkenes to TBHP 1:1.5, results with standard deviation of $\pm 2 \%$ ). 


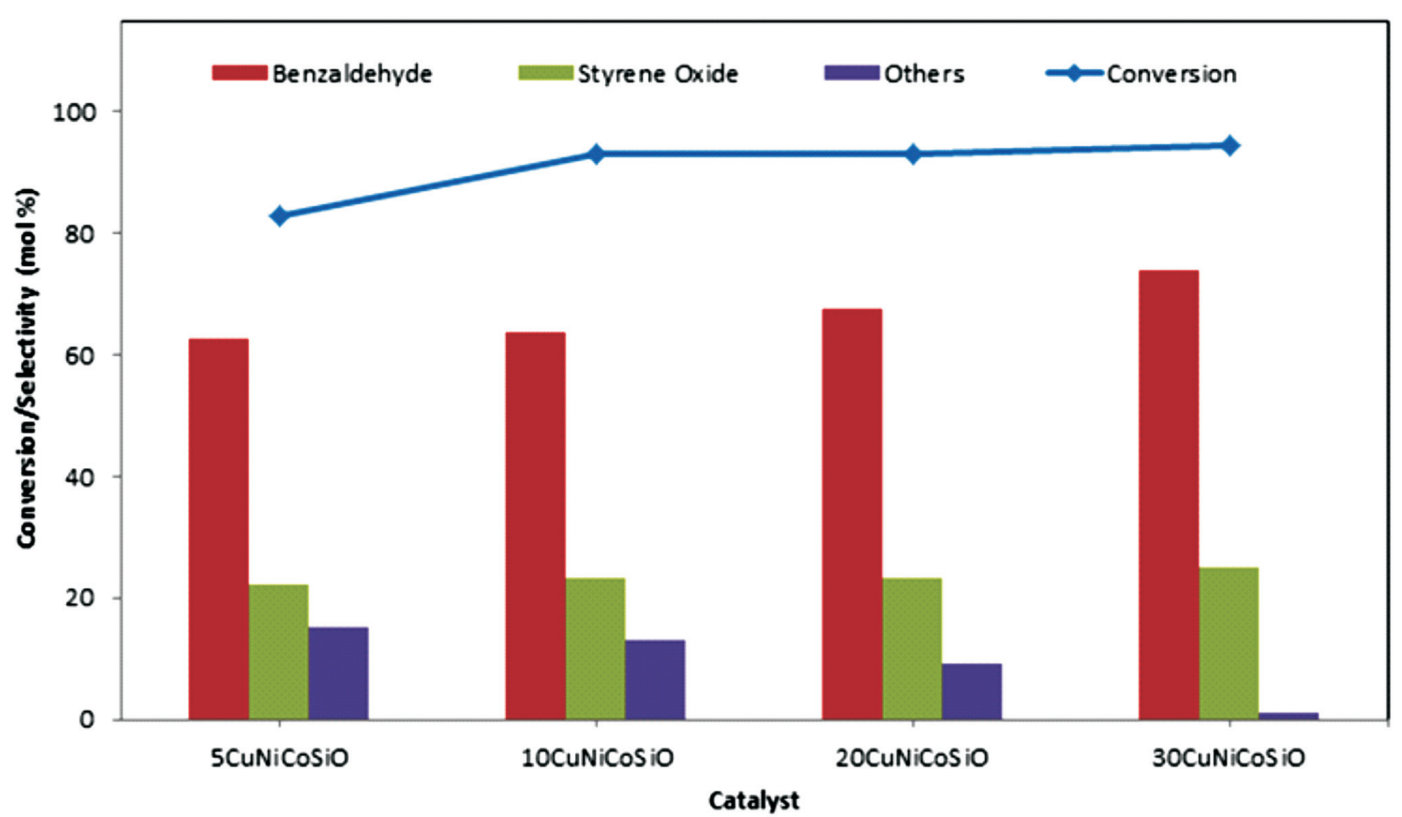

Figure 6 Conversion and selectivity of the trimetallic catalysts for styrene oxidation at $40{ }^{\circ} \mathrm{C}$ after $24 \mathrm{~h}(5 \mathrm{mg}$ catalyst, $0.96 \mathrm{mmol}$ styrene in $2.5 \mathrm{~mL}$ $\mathrm{CH}_{3} \mathrm{CN}$, alkenes to TBHP 1:1.5, results with standard deviation of $\pm 2 \%$ ).

increases for 5 to $30 \mathrm{wt} \%$, the conversion is essentially unchanged from $95 \%$ for $5 \mathrm{CuNiCoSiO}$ to $98 \%$ for the $30 \mathrm{wt} \%$ catalyst, but the selectivities of 4-chlorobenzaldehyde increased from $61 \%$ to $83 \%$, as did the selectivities to 4-chlorostyrene oxide, while the selectivity to other products decreased. Thus best conversion and 4-chlorobenzaldehyde selectivity was observed over the $30 \mathrm{CuNiCoSiO}$ catalyst, likely because more active metal species are available to catalyze the reaction. An appropriate metal loading tends to facilitate specific product selectivity and it may affect the surface properties and number of reactive sites. The trimetallic catalyst systems allow efficient oxidation with a high degree of selectivity. The chlorophenyl-substituted alkene favours oxidative cleavage and formed the aldehyde as a major product.

\subsubsection{Catalytic Oxidation of Cyclohexene}

The catalytic oxidation of cyclohexene with the trimetallic cata- lysts was also investigated with TBHP as oxidant using similar reaction conditions. The results are summarized in Fig. 8. These show again that conversion of cyclohexene increases with the metal loadings.

The $5 \mathrm{wt} \%$ catalyst shows $84 \%$ conversion, while the $30 \mathrm{wt} \%$ catalyst gives $94 \%$ cyclohexene conversion. The dominant products of the oxidation reactions are 2-cyclohexen-1-one and 2-cyclohexen-1-nol, and their selectivity lie between 56-60\% and $30-32 \%$, respectively. The catalytic results show $5-6 \%$ selectivity of cyclohexene oxide for all four catalysts. The other 4-8 \% oxidized products are cis-1,2-cyclohexanediol and trans-1,2cyclohexanediol. In case of cyclic alkenes, there is competition amongst oxidation of the $\mathrm{C}=\mathrm{C}$ double bond and the oxidation of the allylic position. Over the trimetallic catalyst systems, the oxidation of cyclohexene follows the allylic oxidation pathway dominantly and formed 2-cyclohexen-1-one as the major product.

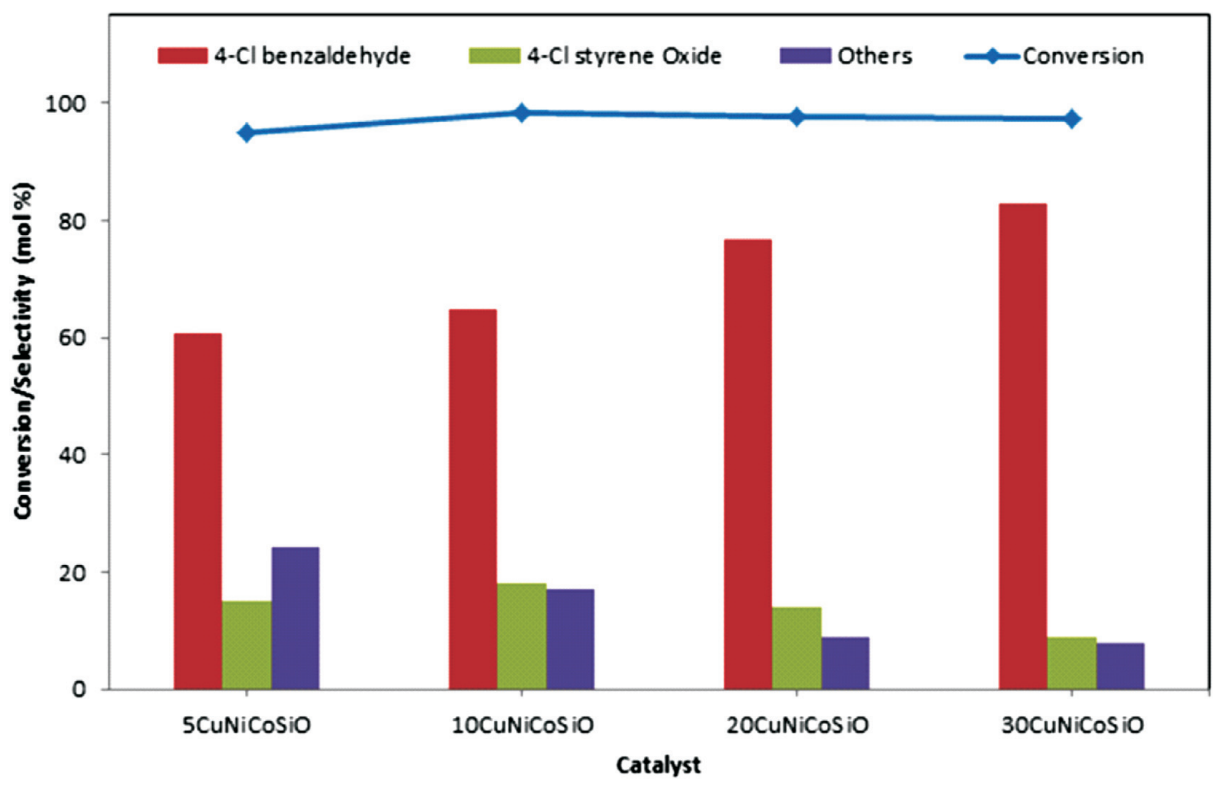

Figure 7 Conversion and selectivity of the trimetallic catalysts for 4-chlorostyrene oxidation at $40{ }^{\circ} \mathrm{C}$ after $24 \mathrm{~h}(5 \mathrm{mg}$ catalyst, $0.72 \mathrm{mmol}$ 4-chlorostyrene in $2.5 \mathrm{~mL} \mathrm{CH}_{3} \mathrm{CN}$, alkenes to TBHP 1:1.5, results with standard deviation of $\pm 2 \%$ ). 


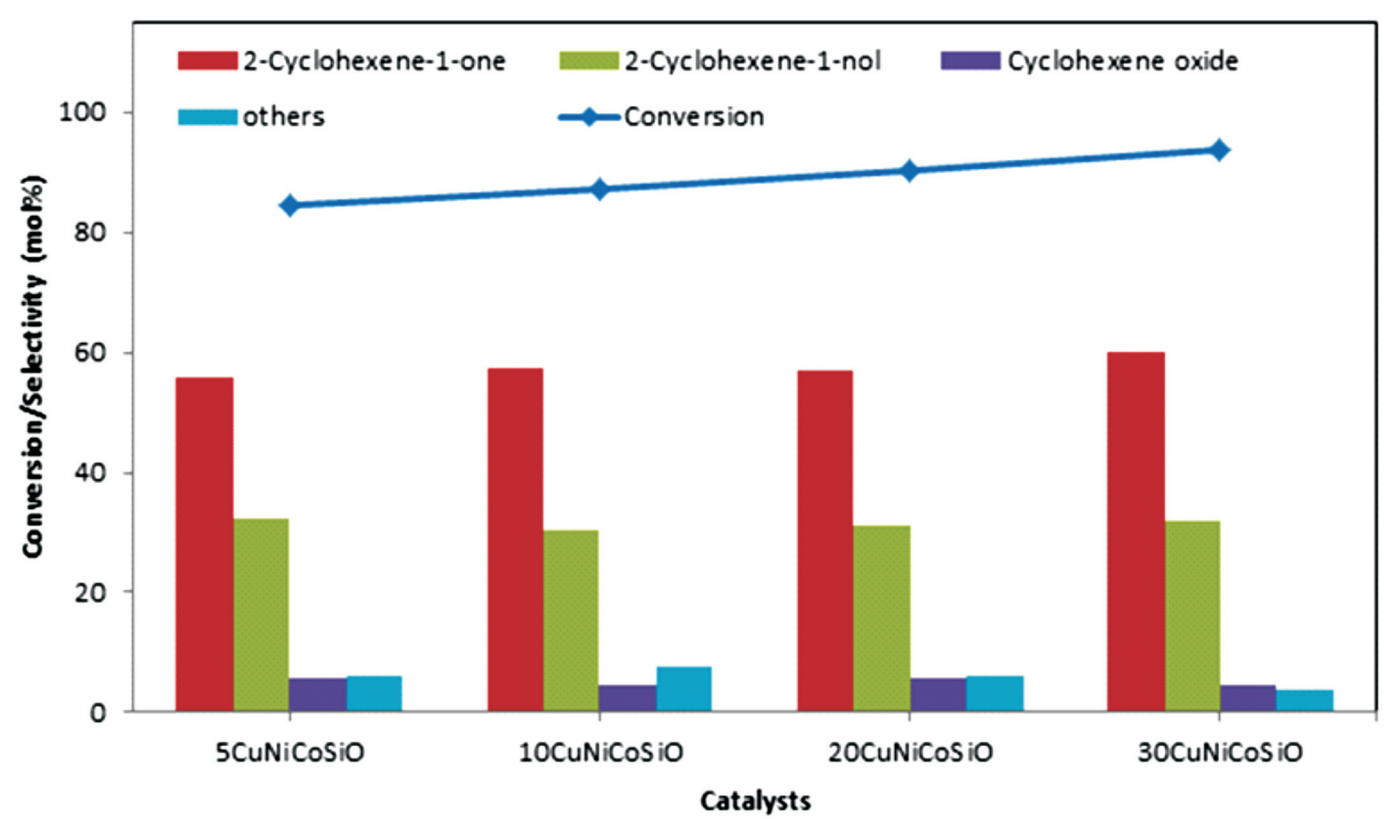

Figure 8 Conversion and selectivity of the trimetallic catalysts for cyclohexene oxidation at $40{ }^{\circ} \mathrm{C}$ after $24 \mathrm{~h}(5 \mathrm{mg}$ catalyst, $1.21 \mathrm{mmol}$ cyclohexene in $2.5 \mathrm{~mL} \mathrm{CH}_{3} \mathrm{CN}$, alkenes to TBHP 1:1.5, results with standard deviation of $\pm 2 \%$ ).

\subsection{Leaching Test and Recyclability}

To confirm the heterogeneity of the catalytic reaction and that the metal did not leach into solution, a leaching test was performed with $10 \mathrm{CuNiCoSiO}$ using styrene as a substrate under optimized reaction conditions.

After four hours of reaction, the catalyst was removed from the hot reaction mixture by filtration and the reaction was continued with the filtrate. After the removal of the catalyst, the conversion had only slightly increased (28\%), very likely be due to the oxidant only, and no metal leaching was observed. The result of the leaching test is shown in Fig. 9.

Catalyst reusability is of major importance in the heterogeneous catalysis system. Recyclability of the catalyst was investigated using styrene as the model substrate with $10 \mathrm{CuNiCoSiO}$ and TBHP under optimum conditions. At the end of each cata- lytic test, the catalyst was filtered off, washed with acetonitrile and dried before being used for further reaction. The catalyst was consecutively reused three times with only slight lowering in catalytic activity (Table 2). Based on the recyclability test and leaching test observation, it can be concluded that the trimetallic catalysts supported on silica are truly heterogeneous and stable because no active metal leaching was observed and the catalyst was reused three times. Metal-support interaction plays an important role and therefore it may be also responsible in enhancing the activity of the catalysts.

\subsection{Plausible Reaction Mechanism}

In the oxidation reactions of the different alkenes in the presence of the heterogeneous catalysts, the reaction probably follows a free-radical mechanism (Fig. 10, shown for styrene)

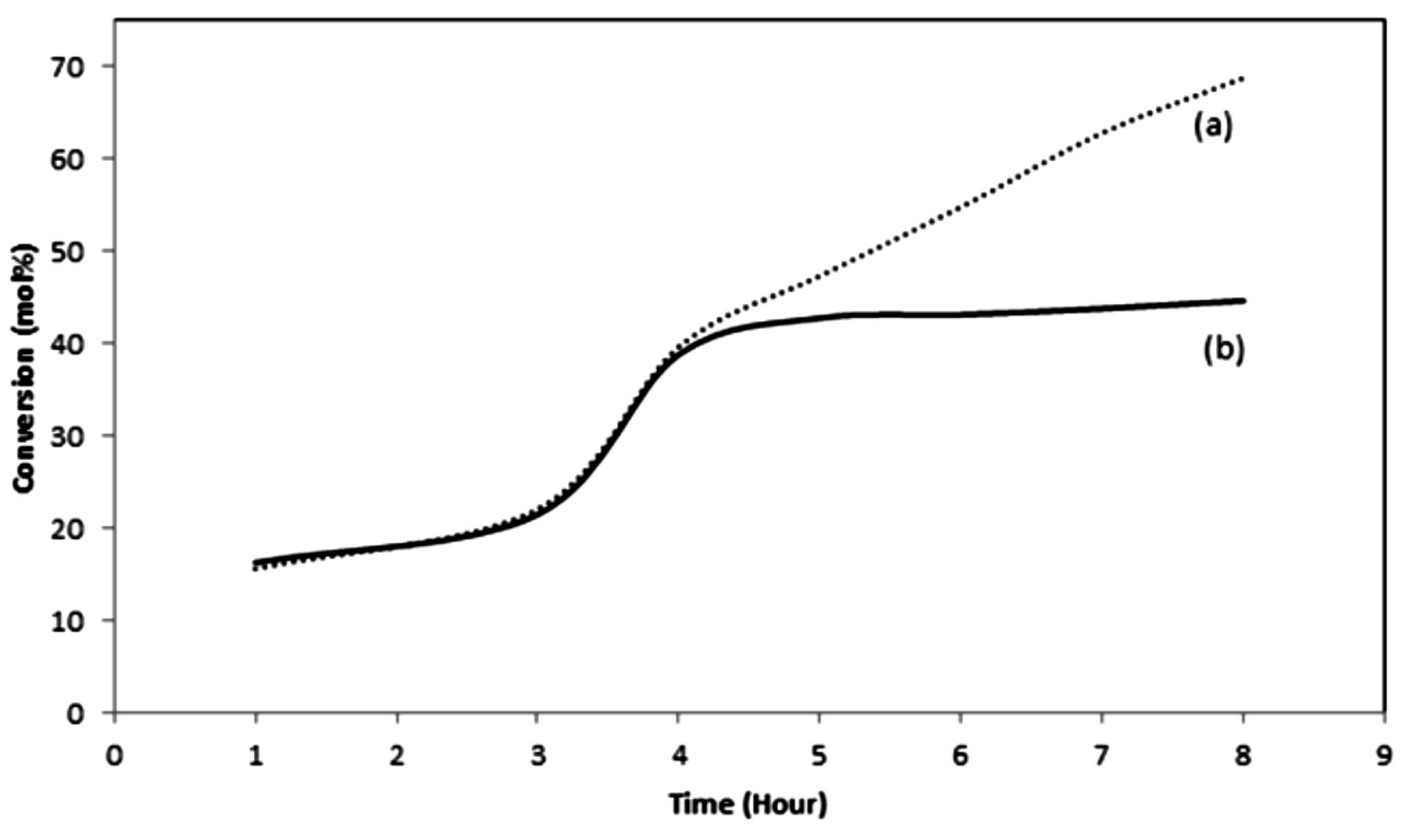

Figure 9 Leaching test of $10 \mathrm{CuNiCoSiO}$ for styrene oxidation at $40{ }^{\circ} \mathrm{C}(\mathrm{a})$ presence of catalyst and (b) after removal of catalyst (required catalyst quantity, $0.96 \mathrm{mmol}$ styrene in $2.5 \mathrm{~mL} \mathrm{CH}_{3} \mathrm{CN}$, alkenes to TBHP 1:1.5, results with standard deviation of $\pm 2 \%$ ). 

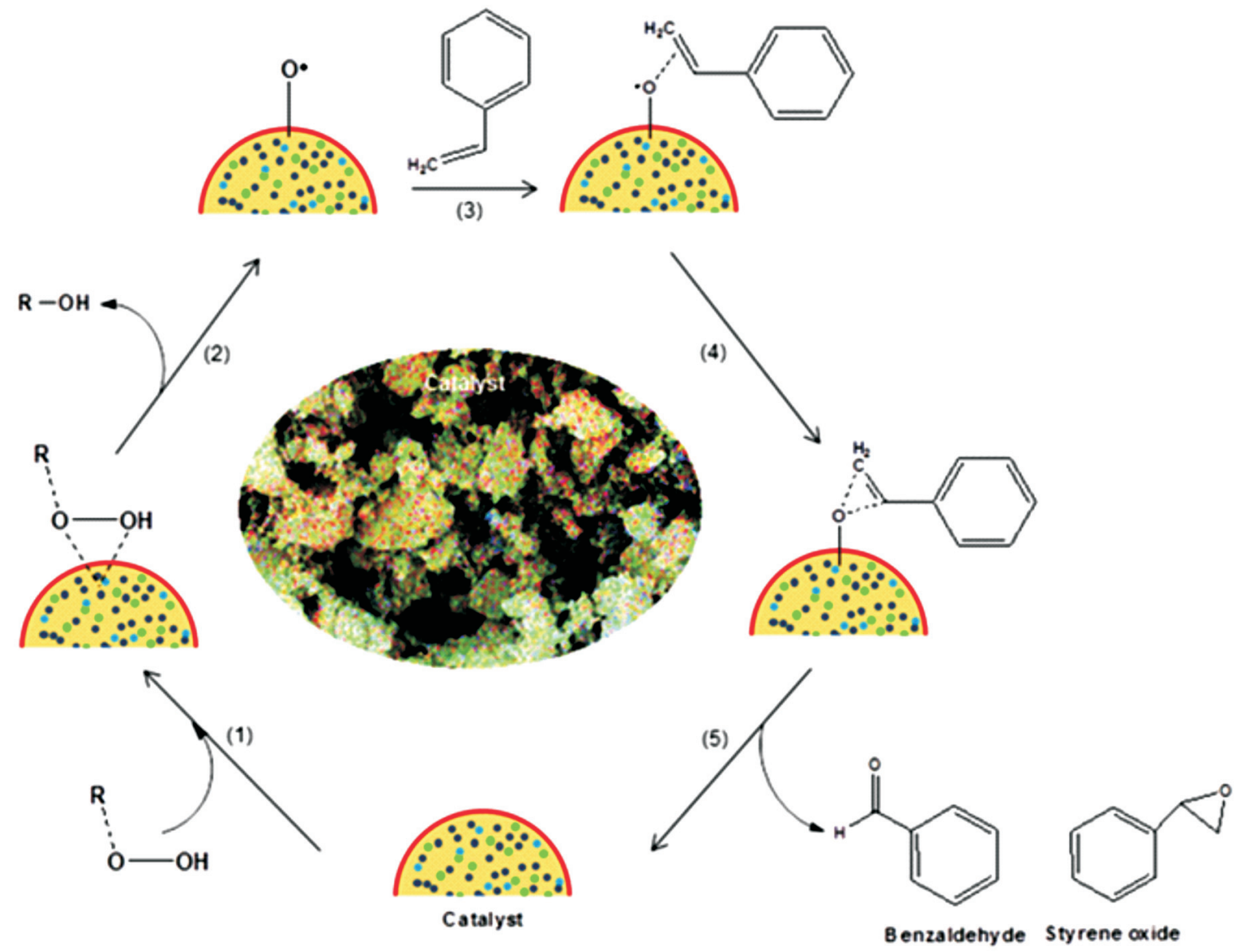

Catalyst

\section{$\mathrm{R}=$ tert-butyl}

Figure 10 Proposed reaction mechanism for styrene oxidation catalyzed by the supported metal oxides.

Table 2 Recyclability test of $10 \mathrm{CuNiCoSiO}$ for styrene oxidation*

\begin{tabular}{|c|c|c|c|c|}
\hline \multirow[t]{2}{*}{ Cycles (reuse) } & \multirow[t]{2}{*}{ Conversion $/ \mathrm{mol} \%$} & \multicolumn{3}{|c|}{ Selectivity/mol\% } \\
\hline & & Benzaldehyde & Styrene oxide & Others \\
\hline First & 87.7 & 62.2 & 24.9 & 13.0 \\
\hline Second & 85.9 & 60.7 & 27.1 & 12.2 \\
\hline Third & 84.1 & 60.4 & 28.2 & 11.4 \\
\hline
\end{tabular}

* Required catalyst quantity, $0.96 \mathrm{mmol}$ styrene in $2.5 \mathrm{~mL} \mathrm{CH}_{3} \mathrm{CN}$, alkenes to TBHP $1: 1.5$, reaction temperature $40{ }^{\circ} \mathrm{C}$.

and thus the interaction of TBHP with the metal oxides on silica is responsible for the formation of the alkylperoxy species (step1). Because the alkylperoxy species is unstable, it undergoes dissociation and forms a metal-peroxo species radical with the loss of alcohol (step 2). In the transition state, the $\pi$-bond formation occurs between the styrene molecule and metal-peroxo species radical (steps $3 \& 4$ ). The radical transformation in the final step favours the cleavage of the $\mathrm{C}=\mathrm{C}$ bond to benzaldehyde with the usage of polar alcohol and water molecules which catalyze the reaction system. The other possibility is that, if $\mathrm{C}=\mathrm{C}$ bond cleavage does not occur, styrene oxide forms (step 5).

\section{Conclusions}

In conclusion, by using the ultrasonic-cavitation impregnation method, bimetallic and trimetallic catalysts supported on silica with high surface area and tuned pore size were prepared. These catalysts were used as efficient catalysts for the functionalization of styrene, 4-chloro styrene and cyclohexene using TBHP at lower temperature. All ternary catalysts showed good catalytic activity and selectivity, due to good dispersion and a cooperative effect produced by the mixed metals on the mesoporous support with high surface area. The trimetallic catalyst systems show more activity as compared to the bimetallic systems. Both the catalysts showed good selectivity towards benzaldehyde and among them the trimetallic systems showed the highest selectivity. Furthermore, these catalysts showed high yields towards benzaldehyde when compared to other catalysts with precious metal catalysts (Au and Ag). ${ }^{9-11}$ The catalysts were recovered by simple filtration and displayed no substantial loss of activity after three recycles. The catalysts showed no active metal species leaching and they were thus heterogeneous catalysts.

\section{Acknowledgements}

We thank the University of KwaZulu-Natal for a postdoctoral fellowship (H.M.P.), Sasol Technology and THRIP (Grant TP1208035643) for financial support. 


\section{References}

1 R.A. Sheldon and J.K. Kochi, Metal-Catalyzed Oxidations of Organic Compounds, Academic Press, New York, 1981.

2 J.D. Chen, H.E.B. Lempers and R.A. Sheldon, Ti-Al- $\beta$ and CrAPO-5 as heterogeneous catalysts for selective oxidations in the liquid phase, Colloids. Surf. A Physicochem. Eng. Asp., 1995, 101, 137-146.

3 T. Punniyamurthy, S. Velusamy and J. Iqbal, Recent advances in transition metal catalyzed oxidation of organic substrates with molecular oxygen, Chem. Rev., 2005, 105, 2329-2364.

4 Q.H. Xia, H.Q. Ge, C.P. Ye, Z.M. Liu and K.X. Su, Advances in homogeneous and heterogeneous catalytic asymmetric epoxidation, Chem. Rev., 2005, 105, 1603-1662.

5 S. Shylesh, C. Srilakshmi, A.P. Singh and B.G. Anderson, One step synthesis of chromium containing periodic mesoporous organosilicas and their catalytic activity in the oxidation of cyclohexane, Micropor. Mesopor. Mat., 2007, 99, 334-344.

6 B. Dong, B. Zhang, H.-Y. Wu, S.-D. Li, K. Zhang and X.-C. Zheng, Direct synthesis, characterization and application in benzaldehyde oxidation of HPWA-SBA-15 mesoporous catalysts, Micropor. Mesopor. Mat., 2013, 176, 186-193.

7 A. Behr and P. Neubert, Applied Homogeneous Catalysis, John Wiley \& Sons, Weinhein, 2012.

8 R.I. Kureshy, I. Ahmad, N.-u.H. Khan, S.H.R. Abdi, K. Pathak and R.V. Jasra, Chiral Mn(III)salen complexes covalently bonded on modified MCM-41 and SBA-15 as efficient catalysts for enantioselective epoxidation of nonfunctionalized alkenes, J. Catal., 2006, 238, 134-141.

9 M. Nemanashi and R. Meijboom, Dendrimer derived titaniasupported Au nanoparticles as potential catalysts in styrene oxidation, Catal. Lett., 2013, 143, 324-332.

10 D. Yin, L. Qin, J. Liu, C. Li and Y. Jin, Gold nanoparticles deposited on mesoporous alumina for epoxidation of styrene: effects of the surface basicity of the supports, J. Mol. Catal. A: Chem., 2005, 240, 40-48.

11 H.-K. Wang, C.-Y. Yi, L. Tian, W.-J. Wang, J. Fang, J.-H. Zhao and W.-G. Shen, $\mathrm{Ag}-\mathrm{Cu}$ Bimetallic nanoparticles prepared by microemulsion method as catalyst for epoxidation of styrene, J. Nanomater., 2012, 2012, 1-8.

12 J. Song, Z. Zhang, T. Jiang, S. Hu, W. Li, Y. Xie and B. Han, Epoxidation of styrene to styrene oxide using carbon dioxide and hydrogen peroxide in ionic liquids, J. Mol. Catal. A: Chem., 2008, 279, 235-238.

13 M. Selvaraj, S.W. Song and S. Kawi, Epoxidation of styrene over mesoporous Zr-Mn-MCM-41, Micropor. Mesopor. Mat., 2008, 110, 472-479.

$14 \mathrm{M}$. Zhu and G. Diao, High catalytic activity of $\mathrm{CuO}$ nanorods for oxidation of cyclohexene to 2-cyclohexene-1-one, Catal. Sci. Technol., 2012, 2, 82-84.

15 C.L. Bracey, A.F. Carley, J.K. Edwards, P.R. Ellis and G.J. Hutchings, Understanding the effect of thermal treatments on the structure of $\mathrm{CuAu} / \mathrm{SiO}_{2}$ catalysts and their performance in propene oxidation, Catal. Sci. Technol., 2011, 1, 76-85.

16 A.L. Ahmad, B. Koohestani, S. Bhatia and S.B. Ooi, Oxidation of styrene to benzaldehyde by anhydrous hydrogen peroxide on $\gamma$-alumina-supported $\mathrm{V}_{2} \mathrm{O}_{5}$ nanoparticle catalysts: optimization studies using response surface methodology, Int. J. Appl. Ceram. Technol., 2012, 9, 588-598.

17 V.R. Choudhary, R. Jha and P. Jana, Selective epoxidation of styrene to styrene oxide by TBHP using simple transition metal oxides $(\mathrm{NiO}$
$\mathrm{CoO}$ or $\mathrm{MoO}_{3}$ ) as highly active environmentally-friendly catalyst, Catal. Commun., 2008, 10, 205-207.

18 F. Figueras and H. Kochkar, Effects of hydrophobicity on the epoxidation of cyclohexene by tert-butyl hydroperoxide on $\mathrm{TiO}_{2}-$ $\mathrm{SiO}_{2}$ mixed oxides, Catal. Lett., 1999, 59, 79-81.

19 H. Nur, S. Ikeda and B. Ohtani, Phase-boundary catalysis of alkene epoxidation with aqueous hydrogen peroxide using amphiphilic zeolite particles loaded with titanium oxide, J. Catal., 2001, 204, 402-408.

20 L. Nie, K.K. Xin, W.S. Li and X.P. Zhou, Benzaldehyde synthesis via styrene oxidation by $\mathrm{O}_{2}$ over $\mathrm{TiO}_{2}$ and $\mathrm{TiO}_{2} / \mathrm{SiO}_{2}$, Catal. Commun., $2007,8,488-492$.

$21 \mathrm{H}$. Salavati and N. Rasouli, Synthesis and characterization of supported heteropolymolybdate nanoparticles between silicate layers of Bentonite with enhanced catalytic activity for epoxidation of alkenes, Mater. Res. Bull., 2011, 46, 1853-1859.

22 W. Lueangchaichaweng, L. Li, Q.-Y. Wang, B.-L. Su, C. Aprile and P.P. Pescarmona, Novel mesoporous composites of gallia nanoparticles and silica as catalysts for the epoxidation of alkene with hydrogen peroxide, Catal. Today, 2013, 203, 66-75.

23 C. Santra, S. Rahman, S. Bojja, O. James, D. Sen, S. Maity, A. Mohanty, S. Mazumderd and B. Chowdhury, Barium, calcium and magnesium doped mesoporous ceria supported gold nanoparticle for benzyl alcohol oxidation using molecular $\mathrm{O}_{2}$, Catal. Sci. Technol., 2013, 3, 360-370.

24 S.K. Badamali, R. Luque, J.H. Clark and S.W. Breeden, Unprecedented oxidative properties of mesoporous silica materials: towards microwave-assisted oxidation of lignin model compounds, Catal. Commun., 2013, 31, 1-4.

25 P. Wu, Z. Xiong, K.P. Loh and X.S. Zhao, Selective oxidation of cyclohexane over gold nanoparticles supported on mesoporous silica prepared in the presence of thio ether functionality, Catal. Sci. Technol., 2011, 1, 285-294.

26 A. Taguchi and F. Schüth, Ordered mesoporous materials in catalysis, Micropor. Mesopor. Mat., 2005, 77, 1-45.

27 R. Martín-Aranda and J. Čejka, Recent advances in catalysis over mesoporous molecular sieves, Top. Catal., 2010, 53, 141-153.

28 D. Astruc, F. Lu and J.R. Aranzaes, Nanoparticles as recyclable catalysts: the frontier between homogeneous and heterogeneous catalysis, Angew. Chem. Int. Ed., 2005, 44, 7852-7872.

29 I.W.C.E. Arends and R.A. Sheldon, Activities and stabilities of heterogeneous catalysts in selective liquid phase oxidations: recent developments, Appl. Catal. A: Gen., 2001, 212, 175-187.

30 I.W. Davies, L. Matty, D.L. Hughes and P.J. Reider, Are heterogeneous catalysts precursors to homogeneous catalysts?, J. Am. Chem. Soc., 2001, 123, 10139-10140.

31 J. Valand, H. Parekh and H.B. Friedrich, Mixed Cu-Ni-Co nanometal oxides: a new class of catalysts for styrene oxidation, Catal. Commun., 2013, 40, 149-153.

32 N. Enomoto, S. Maruyama and Z-e. Nakagawa, Agglomeration of silica spheres under ultrasonication, J. Mater. Res., 1997, 12, 1410-1415.

33 C.G. Ramankutty and S. Sugunan, Surface properties and catalytic activity of ferrospinels of nickel, cobalt and copper, prepared by soft chemical methods, Appl. Catal. A: Gen., 2001, 218, 39-51.

34 V.D.B.C. Dasireddy and H.B. Friedrich, Sooboo Singh, Studies towards a mechanistic in sight into the activation of n-octane using vanadium supported on alkaline earth metal hydroxyapatites, Appl. Catal. A: Gen., 2013, 467, 142-153. 


\section{Online supplement to:}

H.M. Parekh, J.K. Valand and H.B. Friedrich, Heterogeneous oxidation of alkenes: the role of silica-supported bimetallic and trimetallic catalysts, S. Afr. J. Chem., 2016, 69, 227-235.

Table S1 A comparison of the presented catalysts with catalysts reported in literature for styrene oxidation.

\begin{tabular}{|c|c|c|c|c|c|c|c|c|c|c|}
\hline \multirow[t]{2}{*}{ System } & \multirow{2}{*}{$\begin{array}{l}\text { Temp } \\
\left({ }^{\circ} \mathrm{C}\right)\end{array}$} & \multirow[t]{2}{*}{ Solvent } & \multirow[t]{2}{*}{ Oxidant } & \multirow{2}{*}{$\begin{array}{l}\text { Catalyst } \\
\text { (g) }\end{array}$} & \multirow{2}{*}{$\begin{array}{l}\text { Time } \\
\text { (hour) }\end{array}$} & \multirow{2}{*}{$\begin{array}{c}\text { Conversion } \\
(\mathrm{mol} \%)\end{array}$} & \multicolumn{3}{|c|}{ Selectivity $(\mathrm{mol} \%)$} & \multirow[t]{2}{*}{ Ref. } \\
\hline & & & & & & & Benz & $\mathrm{SO}$ & Others & \\
\hline $\mathrm{Au} / \mathrm{TiO}_{2}-\mathrm{W}$ & 70 & Acetonitrile & TBHP & 0.1 & 15 & 18 & 50 & 50 & - & 9 \\
\hline $\mathrm{Au} / \mathrm{TiO}_{2}-\mathrm{s}$ & 70 & Acetonitrile & TBHP & 0.1 & 15 & 25 & 46 & 54 & - & 9 \\
\hline $\mathrm{Au} / \mathrm{Al}_{2} \mathrm{O}_{3}$ & 82 & Benzene & TBHP & 0.1 & 12 & 38.6 & 18 & 65 & 17 & 10 \\
\hline $\mathrm{TiO}_{2} / \mathrm{SiO}_{2}$ & 100 & - & $\mathrm{O}_{2}$ & - & 6 & 99.5 & 43.4 & 8.7 & 47.8 & 20 \\
\hline $\mathrm{Ag}-\mathrm{Cu} / \mathrm{Al}_{2} \mathrm{O}_{3}$ & 82 & Acetonitrile & TBHP & 0.005 & 6 & 94.6 & 33.1 & 66.9 & - & 11 \\
\hline $\mathrm{V}_{2} \mathrm{O}_{5} / \mathrm{Al}_{2} \mathrm{O}_{3}$ & 62.7 & Acetonitrile & $\mathrm{H}_{2} \mathrm{O}_{2}$ & - & 5.15 & 45.73 & 53.14 & 5.98 & 40.88 & 16 \\
\hline $\mathrm{CoO}$ & 82 & - & TBHP & 0.1 & 3 & 47.3 & 0.1 & 73.1 & 26.8 & 17 \\
\hline $\mathrm{NiO}$ & 82 & - & TBHP & 0.1 & 3 & 51.7 & 1.7 & 86.2 & 12.1 & 17 \\
\hline $\mathrm{NiO} / \mathrm{SiO}_{2}$ & 82 & - & TBHP & 0.1 & 3 & 48.8 & 4.3 & 77.7 & 18 & 17 \\
\hline $6 \mathrm{Cu} / \mathrm{Al}_{2} \mathrm{O}_{3}$ & 40 & Acetonitrile & TBHP & 0.005 & 24 & 42.0 & 67 & 20 & 13 & 31 \\
\hline $30 \mathrm{CuNiCo} / \mathrm{Al}_{2} \mathrm{O}_{3}$ & 40 & Acetonitrile & TBHP & 0.005 & 24 & 88.0 & 58.4 & 18.3 & 23.3 & 31 \\
\hline $\mathrm{CuCo} / \mathrm{SiO}_{2}$ & 40 & Acetonitrile & TBHP & 0.005 & 24 & 63.64 & 65.74 & 19.9 & 14.34 & Present work \\
\hline $30 \mathrm{CuNiCo} / \mathrm{SiO}_{2}$ & 40 & Acetonitrile & TBHP & 0.005 & 24 & 94.63 & 73.80 & 25.1 & 1.03 & Present work \\
\hline
\end{tabular}

